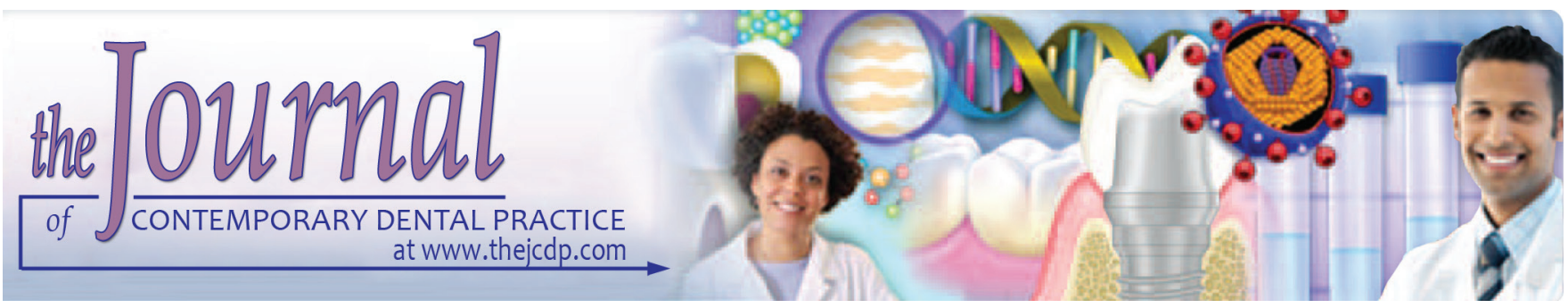

\title{
Evaluation of the Efficacy of Different Mixing Techniques and Disinfection on Microbial Colonization of Polyether Impression Materials: A Comparative Study
}

${ }^{1}$ Youginder Singla, ${ }^{2}$ Renu B Pachar, ${ }^{3}$ Sangeeta Poriya, ${ }^{4}$ Aalok Mishra, ${ }^{5}$ Rajni Sharma, ${ }^{6}$ Anshu Garg

\begin{abstract}
Aim: This study aims to determine the role of mixing techniques of polyether impression materials and efficacy of disinfection on microbial colonization of these impression materials.

Materials and methods: Polyether impression material was mixed using two methods: First by hand mixing (group I) and second using an automixer (group II) with a total of 100 samples. Four microbial strains were studied, which included Escherichia coli, Staphylococcus aureus, Pseudomonas aeruginosa, and Candida albicans. After incubation, the bacterial colonies were counted, and then, disinfectant solution was applied. The effect of disinfection solution was evaluated for each specimen.
\end{abstract}

Results: The surface of polyether impression materials mixed with an automixer has less number of voids and overall a smoother surface as compared with the hand-mixed ones. On comparing the disinfection procedures, i.e., specimens without any disinfection and specimens after disinfection, statistically highly significant difference was seen between all the groups.

Conclusion: We can conclude that impression mixing procedures are important in determining the surface characteristics of the impression and ultimately the colonization of bacteria and also determine the importance of disinfection on microbial colonization.

Clinical significance: This study emphasises the deleterious role of nosocomial infections and specific measures that should be taken regarding the prevention of such diseases. Dental impressions are proved to be a source of such infections and may lead to transmission of such diseases. Thus, proper measures should be taken right from the first step of impression taking to minimizing and preventing such kind of contaminations in clinical practice.

1-4,6 Department of Prosthodontics, Maharaja Ganga Singh Dental College \& Research Centre, Sri Ganganagar, Rajasthan, India

${ }^{5}$ Department of Orthodontics, Maharaja Ganga Singh Dental College \& Research Centre, Sri Ganganagar, Rajasthan, India

Corresponding Author: Youginder Singla, Department of Prosthodontics, Maharaja Ganga Singh Dental College \& Research Centre, Sri Ganganagar, Rajasthan, India, Phone: +919814192252, e-mail: dryksingla@gmail.com
Keywords: Disinfection, Impression material, Microorganisms, Mixing technique.

How to cite this article: Singla Y, Pachar RB, Poriya S, Mishra A, Sharma R, Garg A. Evaluation of the Efficacy of Different Mixing Techniques and Disinfection on Microbial Colonization of Polyether Impression Materials: A Comparative Study. J Contemp Dent Pract 2018;19(3):296-300.

Source of support: Nil

Conflict of interest: None

\section{INTRODUCTION}

Oral cavity is said to be a storehouse of numerous pathogenic and nonpathogenic species of microorganisms, and saliva is a potent source of infection because of these pathogens. Dentists usually come in direct contact with the oral cavity, specifically, saliva and blood in their day-to-day clinical practice. As dental impressions are an important and routine procedure in clinical practice, they are usually contaminated by these microorganisms either through blood or saliva of the patient. ${ }^{1}$ The risk of infection transmitted by saliva and blood has led to an increased concern for and attention to infection control in dental practice. ${ }^{2}$

Reports have shown that $67 \%$ of materials sent to dental laboratories are infected by various microorganisms. ${ }^{3}$ Commonly identified microorganisms in the oral cavity include Staphylococcus species, Streptococcus species, E. coli species, Actinomyces species, Pseudomonas species, Klebsiella pneumoniae, and Candida species. A number of impression materials are used in dental practice, and out of these, polyether elastomeric impression materials are quite popular. It is a copolymer of 1,2-epoxyethane and tetrahydrofuran that is reacted with an $\alpha, \beta$-unsaturated acid, such as crotonic acid, to produce the final polymer and an aromatic sulfonate 
through cationic polymerization. ${ }^{4}$ Mixing techniques used for such impression materials play an important role in determining the surface properties and features of the impression. Hand mixing is the commonly used method in routine clinical practice, while automated machines are also available, which are said to provide with a more homogeneous and smoother mix with better surface qualities. These surface properties are important in the transmission of microorganisms. Role of disinfectants becomes, hereby, important due to prevention of the infections through these dental materials commonly used. Many disinfectants of different compositions and concentrations are readily available in the market. Different types of disinfectants have been compared in earlier studies by various authors regarding their efficacy and utility. Commonly used methods for these are by immersion technique and spray method. Disinfection by soaking in chemical materials covers all the surfaces of impression materials at one time, while spraying is not capable of disinfecting all surfaces effectively and also cannot cover all undercuts. ${ }^{2}$ Thus, keeping in view the relation of mixing technique of the impression materials with their surface properties and role of disinfectants, we planned a study with the aim to determine the role of mixing techniques of polyether impression materials and efficacy of disinfection on microbial colonization of these impression materials.

\section{MATERIALS AND METHODS}

\section{Sample Preparation and Surface Examination}

This prospective experimental study was conducted in the Department of Prosthodontics wherein polyether impression materials were mixed using two methods: First by hand mixing (group I) and second using an automixer (group II). Thus, according to these two methods used, a total of 100 samples were included in the study with 50 samples in each study group. Next, using these two impression methods, impressions were prepared from the standard models available under sterilized conditions. After the complete setting of the impression materials, the prepared models were observed for their surface characteristics under the microscope.

\section{Microbial Sample and Analysis}

In the present study, four microbial strains were used, which included E. coli [American Type Culture Collection (ATCC) strain number 25922], S. aureus (ATCC strain number 29213), P. aeruginosa (ATCC strain number 27853), and C. albicans. Disinfectant spray Deconex (Borer Chemie Inc., Switzerland) was used in this study to check the efficacy of disinfection of the polyether impression materials. All the models though were prepared with sterilized instruments, and in sterile conditions; still, to ensure that the prepared models were sterile during the study, two samples were kept as negative controls and were incubated on tryptic soy broth culture for 24 to 48 hours. The controls were later examined for the bacterial growth. The standard bacterial inoculums were prepared in nutrient broth so as to match the turbidity equivalent of $0.5 \mathrm{McF}$ arland standards. For C. albicans, the samples were taken from Sabouraud dextrose agar (SDA) culture medium. After this, the samples from both the study groups were polluted with the prepared microbial suspensions separately by using sterile test tubes with $1 \mathrm{cc}$ of microbial suspension in each and then incubating the sample at $37^{\circ} \mathrm{C}$ for 24 hours. After the incubation step, the bacterial colonies were transferred into the nutrient broth where the samples were vortexed and the suspension thus, prepared for each sample were inoculated onto Petri dishes containing blood agar. The culture plates were incubated for 24 hours at $37^{\circ} \mathrm{C}$. Bacterial growth was observed in the plates and the colonies were counted using a colony counter. The colonies of C. albicans on SDA medium were counted after 72 hours. Next, to test the efficacy of the disinfectant used, we disinfected all samples except the controls using Deconex disinfectant using the spray method ( 5 puffs for 15 seconds). Thus, a total of 10 samples for each bacterial strain were evaluated from both the groups. To check the efficacy of the disinfectant used, a control group of five samples was taken from each group in which no disinfectant was used. The microbial count from the surface of the disinfected impression materials was checked in the similar manner as discussed earlier.

\section{STATISTICAL ANALYSIS AND RESULTS}

All the values and observations were tabulated and sent for statistical evaluation using statistical software Statistical Package for the Social Sciences version 21 (IBM Inc., Armonk, New York, USA). A p-value <0.005 was considered as statistically significant. Nonparametric tests, such as Mann-Whitney U test and Kruskal-Wallis test were used for intergroup comparisons. In this study, we evaluated the surface characteristics of the polyether impression materials by comparing hand mixing and automixing techniques. Our results showed that the surface of polyether impression materials mixed with an automixer has less number of voids and overall a smoother surface as compared with the hand-mixed ones (Fig. 1). Further, the microbial colony count was done for all the four microorganisms in the study groups and is tabulated in Table 1. It was observed that three microorganisms, i.e., E. coli, S. aureus, and Candida species, showed a statistically significant increase when we compared hand-mixed samples 


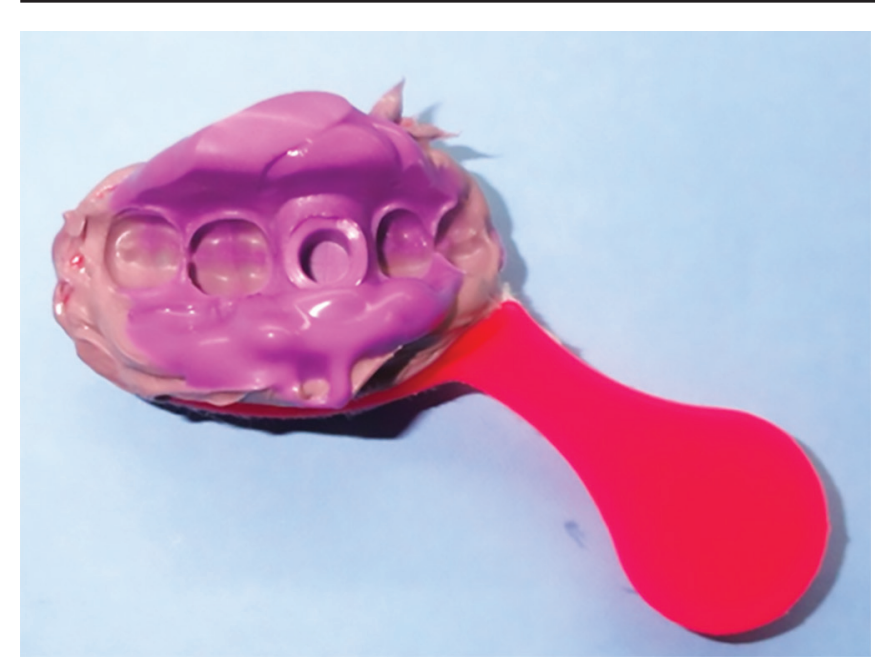

Fig. 1: Impression made using polyether mixed with an automixer showed lesser voids and smoother surfaces

with the automixed ones. Nevertheless, P. aeruginosa did not show any significant difference in the count when both the methods were compared. Further, on comparing the disinfection procedures, i.e., specimens without any disinfection and specimens after disinfection, statistically highly significant difference was seen between all the groups $(\mathrm{p}<0.001)$.

\section{DISCUSSION}

We know that the oral cavity is a major source of microorganisms as it contains around 600 species of microbes. Thus, saliva carries both pathogenic and nonpathogenic bacteria, virus, and fungi. Dentists usually come across potentially harmful microorganisms in their day-to-day clinical practice. As dental impressions are an important and routine procedure in clinical practice, they are usually contaminated by these microorganisms either through blood or saliva of the patient. ${ }^{1}$ Moura et al, ${ }^{5}$ in their study, reported a significantly high level of microbial count from patient's mouth by irreversible hydrocolloid impressions. Al-Jabrah et $\mathrm{al}^{6}$ also reported that dental professionals are at three times higher risk than the general population of contacting infection and developing the carrier state. The most frequently identified microorganisms include Streptococcus species, Staphylococcus species, E. coli species, Actinomyces species, Pseudomonas species, K. pneumoniae, and Candida species. ${ }^{7}$ Therefore, the step of disinfection of the impressions is very important to prevent contamination and spread of infection from the infected patients. Egusa et $\mathrm{al}^{8}$ reported that alginate impressions taken from patient's mouths contain hazardous microorganisms, such as S. aureus, methicillin-resistant Staphylococcus, C. albicans, and P. aeruginosa with rates of 55.6, 25.9, 25.9 , and $5.6 \%$ respectively. In the present study, we studied four potent microorganisms, which were E. coli, S. aureus, P. aeruginosa, and C. albicans. Colony-forming units (CFU)/ $\mathrm{mL}$ were calculated for each microorganism and comparisons were made for both groups I and II. Polyether elastomeric impression materials are the most commonly used impression materials in clinical practice. Hand mixing of these impression materials leaves a nonuniform surface, with surface voids and surface roughness in comparison with the automixing procedure, which produces a uniform, bubble-free homogenous mix. ${ }^{9}$ Thus, the surface properties, which are determined by the mixing technique of the impression material, influence the attachment of microorganisms and subsequently affect the disinfection of these materials.

In the present study, we also observed similar findings, which show that the surface of polyether impression materials mixed with an automixer had less number of voids and overall a smoother surface as compared with the hand-mixed ones. Previously, studies have also reported that show a relationship between the disinfection process, wettability, and mass change of impression materials. ${ }^{10,11}$ In contrast, Guler et al ${ }^{12}$ reported that the bacterial attachment to hand-mixed polyether samples was less than that to automixed samples. They explained it based on the fact that they used polished surface stainless steel molds to prepare the samples, which contributed to this result. Due to these molds, a smooth-surfaced impression was prepared, and probably, the bubbles were present subsurface. Our study shows that three microorganisms, i.e., E. coli, S. aureus, and Candida species, showed a statistically significant increase with hand-mixed procedure. On the contrary, Guler et al ${ }^{12}$ reported that only E. coli counts were higher in hand-mixed materials, while no other statistically significant differences as a result from mixing methods were observed. Role of disinfectants for

Table 1: Comparison of mean CFU of E. coli, S. aureus, P. aeruginosa, and C. albicans colony counts among the study groups

\begin{tabular}{|c|c|c|c|c|c|c|c|c|}
\hline & \multicolumn{2}{|c|}{ E. coli count } & \multicolumn{2}{|c|}{ S. aureus count } & \multicolumn{2}{|c|}{$P$. aeruginosa count } & \multicolumn{2}{|c|}{ C. albicans count } \\
\hline & $\begin{array}{l}\text { Control group } \\
\text { (without } \\
\text { disinfection) }\end{array}$ & $\begin{array}{l}\text { Study } \\
\text { group (after } \\
\text { disinfection) }\end{array}$ & $\begin{array}{l}\text { Control group } \\
\text { (without } \\
\text { disinfection) }\end{array}$ & $\begin{array}{l}\text { Study } \\
\text { group (after } \\
\text { disinfection) }\end{array}$ & $\begin{array}{l}\text { Control group } \\
\text { (without } \\
\text { disinfection) }\end{array}$ & $\begin{array}{l}\text { Study } \\
\text { group (after } \\
\text { disinfection) }\end{array}$ & $\begin{array}{l}\text { Control group } \\
\text { (without } \\
\text { disinfection) }\end{array}$ & $\begin{array}{l}\text { Study } \\
\text { group (after } \\
\text { disinfection) }\end{array}$ \\
\hline $\begin{array}{l}\text { Group I (hand } \\
\text { mixed) }\end{array}$ & $68 \times 10^{5}$ & $48 \times 10^{3}$ & $32 \times 10^{5}$ & 2020 & $60 \times 10^{5}$ & 5400 & $45 \times 10^{3}$ & 6260 \\
\hline $\begin{array}{l}\text { Group II } \\
\text { (automixed) }\end{array}$ & $46 \times 10^{5}$ & $21 \times 10^{3}$ & $41 \times 10^{5}$ & 1050 & $58 \times 10^{5}$ & 4960 & $31 \times 10^{3}$ & 4530 \\
\hline
\end{tabular}


impressions is already discussed and justified. In lieu of this, the most common chemical disinfectants used by dentists are alcohols, aldehydes, chlorine combination, phenols, biguanides, iodide combinations, and ammonium. ${ }^{13}$ For our study, we preferred Deconex disinfectant using the spray method. It is an alcohol-based disinfectant agent effective against many pathogenic microorganisms, especially $P$. aeruginosa and $S$. aureus, as reported by various authors. ${ }^{14}$ In this study, we compared specimens in two groups, one of which was without spraying the specimens with disinfectant solution and the other group contained specimens after spraying the disinfectant solution. On comparing, it was observed that a statistically highly significant difference was seen in the results with the first group showing higher colony counts than the group on which disinfectant was used. In routine procedures, disinfectants are applied to polyether impression materials to prevent transmission from contaminated materials to health care workers. It is reported that health care workers could transmit bacteria to patients; thus, the impression materials become possible sources of nosocomial infections in a health setup. ${ }^{15-17}$

The clinical significance of this study can be described based on the fact that the nosocomial infections must be recognized, and specific measures should be taken regarding the prevention of such diseases. Dental impressions have been proved to be a source of such infections and may lead to transmission of such diseases. Thus, proper measures should be taken right from the first step of impression taking to minimizing and preventing such kind of contaminations in the clinical practice. To look at the drawbacks of this study, first, after reviewing the literature, we have come across few studies that have been reported, which emphasized on the duration of exposure to disinfectant on the surfaces of the impressions. However, in our study, we did not consider this as comparative criteria. This could definitely put more clarity on the use and benefits of disinfectants in clinical practice. Second, as this study is performed in the laboratory setup under controlled conditions, results may vary when we perform such studies taking samples directly from patients. Thus, the need for clinical studies in this field is high to test the efficacy of disinfection time and the mixing methods.

\section{CONCLUSION}

The study results advocate that impression mixing procedures are imperative in determining the surface characteristics of the impression and ultimately the colonization of bacteria. In addition, clinicians must emphasize on the right use of disinfectants for such impressions to prevent cross-contamination and spread of infection. Hence, clinicians can logically select and utilize the suitable mixing technique as per scenario; however, large-scale studies are required to further substantiate the result obtained in this study.

\section{CLINICAL SIGNIFICANCE}

Dental impressions could be a source of infections and may lead to transmission of such diseases. Therefore, proper measures should be taken right from the first step of impression taking to minimize and prevent such kind of contaminations in clinical practice.

\section{REFERENCES}

1. Flanagan DA, Palenik CJ, Setcos JC, Miller CH. Antimicrobial activities of dental impression materials. Dent Mater 1998 Nov;14(6):399-404.

2. Schutt RW. Bactericidal effect of a disinfectant dental stone on irreversible hydrocolloid impressions and stone casts. J Prosthet Dent 1989 Nov;62(5):605-607.

3. Powell GL, Runnells RD, Saxon BA, Whisenant BK. The presence and identification of organisms transmitted to dental laboratories. J Prosthet Dent 1990 Aug;64(2):235-237.

4. Shilinburg, HT.; Hobo, S.; Whitsett, LD.;Jacobi, R.; Brackett, SE. Fundamentals of fixed prosthodontics. 3rd ed. Canada: Quintessence Publisher; 1997. pp. 302-305.

5. Moura DC, Moura WL, França FM, Martins GA, Feltrim PP, Zanetti RV. Disinfection of irreversible hydrocolloid impressions with sodium hypochlorite steam: assessment of antimicrobial efficacy. Rev Odonto 2010 Apr;25(2):182-187.

6. Al-Jabrah O, Al-Shumailan Y, Al-Rashdan M. Antimicrobial effect of 4 disinfectants on alginate, polyether, and polyvinyl siloxane impression materials. Int J Prosthodont 2007 May-Jun;20(3):299-307.

7. Pang SK, Millar BJ. Cross infection control of impressions: a questionnaire survey of practice among private dentists in Hong Kong. Hong Kong Dent J 2006 Jan;3:89-93.

8. Egusa H, Watamoto T, Matsumoto T, Abe K, Kobayashi M, Akashi Y, Yatani H. Clinical evaluation of the efficacy of removing microorganisms to disinfect patient-derived dental impressions. Int J Prosthodont 2008 Nov-Dec;21(6):531-538.

9. Lepe X, Johnson GH, Berg JC, Aw TC. Effect of mixing technique on surface characteristics of impression materials. J Prosthet Dent 1998 May;79(5):495-502.

10. Melilli D, Rallo A, Cassaro A, Pizzo G. The effect of immersion disinfection procedures on dimensional stability of two elastomeric impression materials. J Oral Sci 2008 Dec;50(4):441-446.

11. Samaranayake LP, Hunjan M, Jennings KJ. Carriage of oral flora on irreversible hydrocolloid and elastomeric impression materials. J Prosthet Dent 1991 Feb;65(2):244-249.

12. Guler U, Budak Y, Ruh E, Ocal Y, Canay S, Akyon Y. Effect of mixing techniques on bacterial attachment and disinfection time of polyether impression material. Eur J Dent 2013 Sep;7(Suppl 1):S54-S59.

13. Ahmad S, Tredwin CJ, Nesbit M, Moles DR, Effect of immersion disinfection with Perform-ID on alginate, an alginate alternative, an addition-cured silicone and resultant type III gypsum casts. Br Dent J 2007 Jan;202(1):E1, disussion 36-37.

14. Azimi Hoseini S, Shahcheraghi F, Ghaemmaghami A. Evaluation of the clinical efficacy of quaternary ammonium components (QAC) as surface disinfectant. J Dent Tehran Univ Med Sci 2006 Jul;3(4):190-194. 
15. Ten Broeke-Smits NJ, Kummer JA, Bleys RL, Fluit AC, Boel CH. Hair follicles as a niche of Staphylococcus aureus in the nose; is a more effective decolonisation strategy needed? J Hosp Infect $2010 \mathrm{Nov} ; 76(3): 211-214$

16. Liguori G, Bagattini M, Gallè F, Quartucci V, Di Onofrio V, Negrone $M$, Triassi M. Microbiological evaluation of the efficacy of two new biodetergents on multidrug resistant nosocomial pathogens. Ann Clin Microbiol Antimicrob 2009 Dec;8:35.

17. Uneke CJ, Ogbonna A, Oyibo PG, Onu CM. Bacterial contamination of stethoscopes used by health workers: public health implications. J Infect Dev Ctries 2010 Aug;4(7):436-441. 